\title{
OPEN
}

\section{Differing trends in the incidence of vascular comorbidity in MS and the general population}

\begin{abstract}
Ruth Ann Marrie, MD, PhD; John Fisk, PhD; Helen Tremlett, PhD; Christina Wolfson, PhD; Sharon Warren, PhD; James Blanchard, PhD; Scott B. Patten, MD, PhD; for the CIHR Team in the Epidemiology and Impact of Comorbidity on Multiple Sclerosis
\end{abstract}

\begin{abstract}
Background: Although the adverse effects of vascular comorbidities are increasingly recognized in multiple sclerosis (MS), the epidemiology of these conditions remains poorly understood. Methods: Using population-based administrative data, we identified 44,452 Canadians with MS and 220,849 age-, sex- and geographically matched controls. We applied validated definitions to estimate the incidence of diabetes, hypertension, hyperlipidemia, and ischemic heart disease (IHD) from 1995 to 2005 . Results: Of the MS cases, 31,757 (71.4\%) were in female participants, with a mean (SD) age at the index date of 43.8 (13.7) years. Over time, the agestandardized incidence of diabetes rose more in the MS population (incidence rate ratio [IRR] per year 1.06; 95\% confidence interval [CI] 1.03-1.08) than in the matched population (IRR per year 1.02; 95\%

$\mathrm{Cl}$ 1.01-1.03). Temporal trends in the age-standardized incidence of hyperlipidemia, hypertension, and IHD were similar in both populations. Among those aged 20-44 years, the incidence of IHD was higher in the MS population (IRR 1.59; 95\% Cl 1.19-2.11). The increased incidence of IHD in the MS population was attenuated among those aged 60 years and older (IRR 1.01; 95\% Cl 0.97-1.06). Conclusions: The incidence rates of diabetes, hypertension, and hyperlipidemia are rising within the MS population. Programs to systematically prevent and treat these conditions are needed. Neurol Clin Pract 2016;6:120-128
\end{abstract}

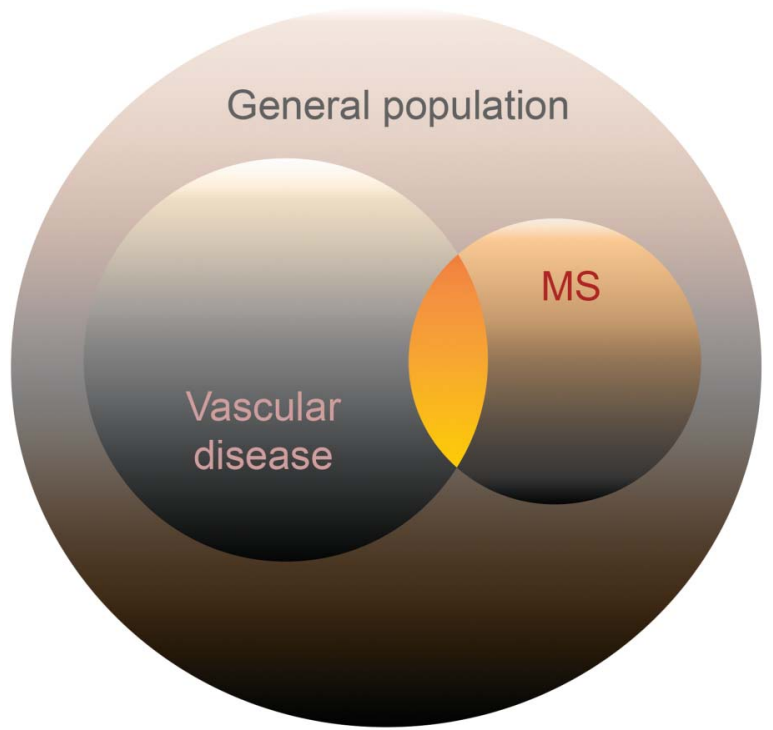

Departments of Internal Medicine (RAM) and Community Health Sciences (RAM, JB), University of Manitoba, Winnipeg; Departments of Psychiatry and Medicine (JF), Dalhousie University, Halifax; Department of Medicine (Neurology) (HT), University of British Columbia, Vancouver; Department of Epidemiology and Biostatistics and Occupational Health (CW), McGill University, Montreal; Faculty of Rehabilitation Medicine (SW), University of Alberta, Edmonton; and Department of Community Health Sciences (SBP), University of Calgary, Canada.

Funding information and disclosures are provided at the end of the article. Full disclosure form information provided by the authors is available with the full text of this article at Neurology.org/cp. The Article Processing Charge was paid by Canadian Institutes for Health Research.

Coinvestigators are listed at Neurology.org/cp.

This is an open access article distributed under the terms of the Creative Commons Attribution-NonCommercialNoDerivatives License 4.0 (CC BY-NC-ND), which permits downloading and sharing the work provided it is properly cited. The work cannot be changed in any way or used commercially.

Correspondence to: rmarrie@hsc.mb.ca 
W

hile prevalence is more readily measured, incidence estimates are critical for determining disease risk. These estimates are particularly useful for etiologic studies, and are also relevant for pharmacovigilance and population disease surveillance. Although several studies have reported the prevalence of medical comorbidities within the multiple sclerosis (MS) population, few have reported the incidence of medical comorbidities in this population. ${ }^{1}$

Few population-based studies of incident comorbidities in MS have focused on common conditions such as hypertension, ${ }^{1}$ and none has reported age-specific incidence estimates, even though the burden of comorbidity increases with age. ${ }^{2}$ Given the recognized adverse effects of vascular comorbidities (diabetes, hypertension, hyperlipidemia, ischemic heart disease [IHD]) on outcomes in MS such as disability progression, ${ }^{3}$ their epidemiology requires attention as a better understanding of the associations between comorbidity and MS is necessary to support studies to evaluate the pathophysiology of these associations.

We aimed to assess the age-specific incidence of vascular comorbidity in MS, temporal trends in the incidence of vascular comorbidity, and differences in the incidence of comorbidity according to sex because of the strong female predominance in MS. We compared these findings in the MS population to those in matched controls.

\section{METHODS}

\section{Administrative data}

We conducted this cohort study in 4 Canadian provinces-British Columbia, Manitoba, Quebec, and Nova Scotia—over the years 1995-2005. These provinces capture nearly 43\% of the Canadian population, ${ }^{4}$ and each has procedures for accessing their anonymized, administrative (health) data, which capture nearly all residents in their jurisdictions. The data accessed included population registries, and hospital and physician claims for the years 1990-2010, except in British Columbia, where data extended to 2008. . $^{5-7}$ These datasets can be linked within provinces using a unique identification number. The population registries capture sex, region of residence (postal code), and dates of birth and death. Dates of health care coverage are recorded, including when an individual migrates in or out of the province. Hospital claims include dates of admission and discharge, and diagnosis codes classified using the International Classification of Disease (ICD)-9 or ICD-10 system, depending on the year. Physician claims include service date and diagnosis. Due to provincial privacy regulations, which prevent line-level data from leaving the province of origin, we performed analyses in parallel at each site, adopting the approach of the Canadian Network for Observational Drug Effect Studies. ${ }^{8}$

\section{Standard protocol approvals, registrations, and patient consents}

The Research Ethics Boards at each participating site approved the study. The relevant body within each province (British Columbia Ministry of Health, Manitoba Health Information Privacy Committee, Commission d'Acces a l'Information du Quebec, Health Data Nova Scotia) approved administrative data access.

\section{Study populations}

Using a validated case definition, ${ }^{9}$ we identified all persons with MS in each province as those with $\geq 3$ hospital or physician claims for MS (ICD-9/10 = 340/G35). We selected a matched cohort from the general population, excluding individuals with any diagnostic codes (ICD-9/10) for demyelinating disease (see appendix e-1 at Neurology.org/cp). Statistical efficiency is optimized at 4 to 6 matches, therefore we identified up to 5 matches for each case, matched on sex, year of birth, and region of residence (postal [mailing] code or first 3 digits of the postal code if unable to match on the full postal code). For each person with MS, we assigned the date of the first health claim for demyelinating disease as the date of diagnosis. The same date (index date) was assigned to their matched controls. 
Table Data sources, number of cases and controls, age, and sex

\begin{tabular}{|c|c|c|c|c|}
\hline Characteristics & British Columbia & Manitoba & Quebec & Nova Scotia \\
\hline $\begin{array}{l}\text { Provincial population in } \\
2001^{a}\end{array}$ & $3,868,875$ & $1,103,700$ & $5,939,715$ & 897,570 \\
\hline Multiple sclerosis cases & 14,049 & 5,797 & 21,368 & 4,124 \\
\hline Female & $10,072(71.7)$ & $4,140(71.4)$ & 15,069 (70.5) & $3,060(74.2)$ \\
\hline Age at index date, $y$ & 44.4 (13.0) & 41.8 (13.5) & $43.7(14.4)$ & 42.5 (12.5) \\
\hline Matched controls & 70,217 & 28,807 & 106,832 & 20,526 \\
\hline Female & $50,344(71.7)$ & 20,566 (71.4) & 75,338 (70.5) & $15,219(74.1)$ \\
\hline Age at index date, $y$ & 44.4 (13.0) & 41.8 (13.5) & 43.7 (14.4) & 42.5 (12.5) \\
\hline
\end{tabular}

\section{Comorbidities}

In each province, we applied case definitions for diabetes, hypertension, hyperlipidemia, and IHD that were validated in Manitoba and Nova Scotia (appendix e-1). ${ }^{10}$ To estimate incidence, we required a 5 -year run-in period preceding the first comorbidity claim to ensure that comorbidity cases were truly incident. In the MS cohort, a comorbidity case was considered incident if the first comorbidity claim occurred after the date of MS diagnosis. For the matched cohort, a comorbidity case was considered incident if the first comorbidity claim occurred after the index date assigned to their matched case. Artifactual drops in incidence can occur at the end of the study period because new cases lack sufficient follow-up time to meet the case definition. Therefore we report incidence for 1995-2005. Due to small cell sizes in some provinces, age was categorized as $20-44,45-59$, and $\geq 60$ years and we examined age effects using average annual age-specific incidence over the study period. We age-standardized findings to the 2001 Canadian population (census year closest to study midpoint) using the direct method, and calculated 95\% confidence intervals (CI) assuming a Poisson distribution. Cell sizes $<5$ were suppressed to comply with privacy requirements, limiting the ability to model crude rates. Therefore we modeled age-standardized incidence using Poisson regression, adjusting for year and sex. ${ }^{11}$ This approach controls for age effects without introducing age in the model as a covariate. ${ }^{11}$ We pooled province-specific estimates using random-effects meta-analysis. We report $I^{2}$ (measure of heterogeneity) and $\tau^{2}$ (measure of between study variance) with forest plots to illustrate variation in estimates across provinces (see appendix e-1).

Analyses were performed using SAS V9.3 (SAS Institute Inc., Cary, NC) and an Excel spreadsheet for meta-analyses. ${ }^{12}$

\section{RESULTS}

We identified 44,452 MS cases, 31,757 (71.4\%) of whom were female, and 220,849 matched controls (table). All incidence rates are pooled estimates from random effects meta-analysis, reported per 100,000 persons per year (95\% CI). In 1995 and 2005, the highest crude incidence rates in both populations were for hypertension (figure 1, A and B). The incidence of all comorbidities increased with age in the MS (figures e-1A-e-4A) and matched (figures $\mathrm{e}-1 \mathrm{~B}-\mathrm{e}-4 \mathrm{~B})$ populations.

\section{Diabetes}

In 2005, the crude incidence of diabetes in the MS population was 765.9, while it was 740.7 in the matched population (figure 1, A and B). Adjusting for year and sex, the age-standardized incidence of diabetes did not differ between populations over the study period (incidence rate ratio [IRR] $0.90 ; 0.79-1.02$, figure 2). The age-standardized incidence of diabetes was $25 \%$ 
Figure 1 Annual incidence of comorbidity per 100,000 persons with multiple sclerosis (A) and in 100,000 persons in the matched population (B) in 1995 and 2005
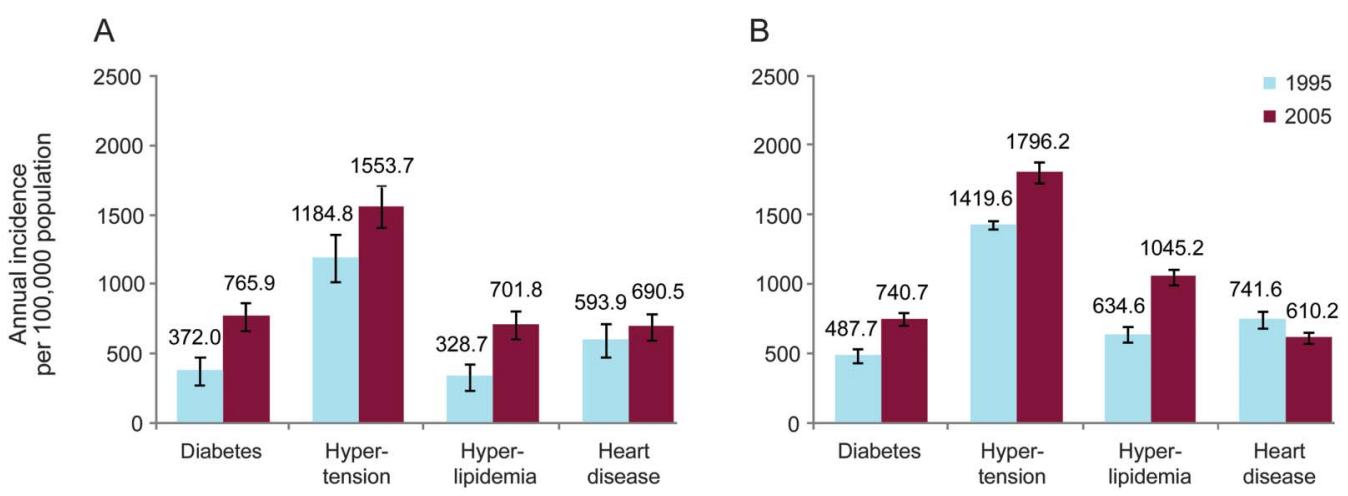

lower in women than men (IRR 0.75; 0.72-0.78, figure e-5). Average annual age-specific incidence rates also did not differ between the MS and matched populations (data not shown). There was an interaction between population and year $(p=0.04)$; the agestandardized incidence of diabetes increased more (IRR 1.06; 1.03-1.08, figure e-6) in the MS population than in the matched population (IRR $1.02 ; 1.01-1.03$, figure e-7).

\section{Hypertension}

In 2005, the crude incidence of hypertension in the MS population was 1,553.7, while it was 1,796.2 in the matched population (figure 1, A and B). Adjusting for year and sex, the agestandardized incidence of hypertension was lower in the MS population than in the matched population over the study period (IRR $0.87 ; 0.75-0.99$, figure 3 ). The age-standardized incidence of hypertension did not differ between women and men (IRR 0.98; 0.84-1.15, figure e-8), and was stable over time (IRR per year 1.02; 0.99-1.05, figure e-9).

The lower overall incidence of hypertension in the MS population appeared to reflect differences in the incidence rates between the 2 populations for persons aged $\geq 60$ years ( $p$ for interaction $=0.021)$. The incidence of hypertension did not differ between the populations for those aged $20-44$ years (IRR $0.98 ; 0.90-1.08$ ), or those aged 45-59 years (IRR 0.94; $0.85-1.04)$. However, among those aged $\geq 60$ years, the incidence of hypertension was lower in the MS population (IRR 0.75; 0.60-0.95, figure e-10).

Figure 2 Forest plot of the adjusted association of diabetes incidence and population, 1995-2005

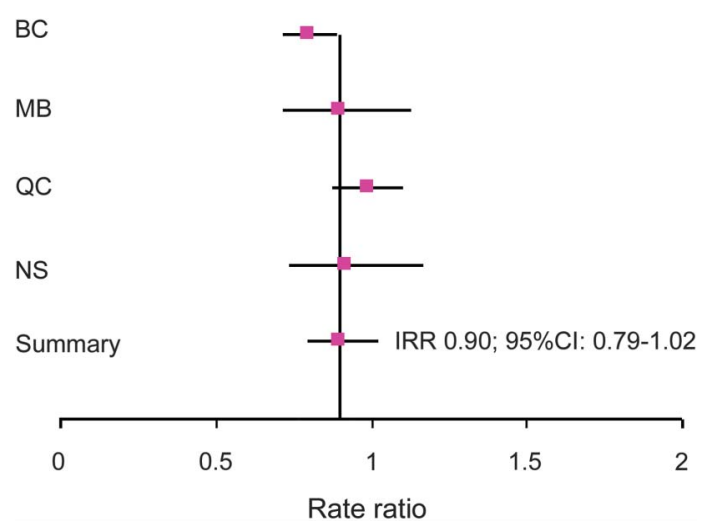

$\tau^{2}=0.16, I^{2}=68.7(p=0.0224) . \mathrm{BC}=$ British Columbia; $\mathrm{Cl}=$ confidence interval; IRR = incidence rate ratio; $\mathrm{MB}=$ Manitoba; NS = Nova Scotia; QC $=$ Quebec. 
Figure 3 Forest plot of the adjusted association of hypertension incidence and population, 1995-2005

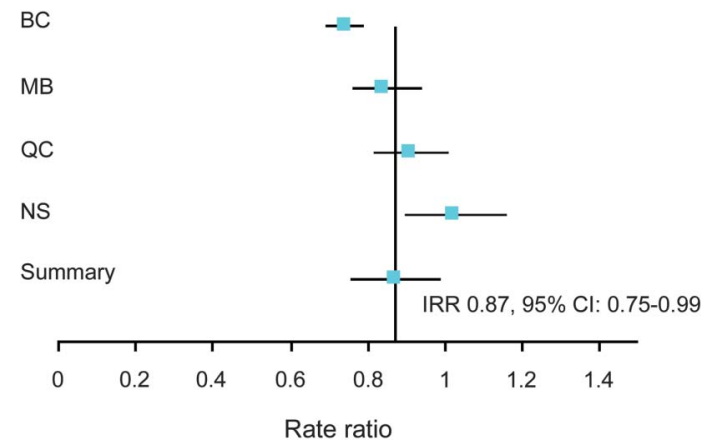

$\tau^{2}=0.060, I^{2}=86.9(p<0.0001) . \mathrm{BC}=$ British Columbia; $\mathrm{Cl}=$ confidence interval; IRR = incidence rate ratio; $\mathrm{MB}=$ Manitoba; NS = Nova Scotia; $\mathrm{QC}=$ Quebec.

\section{Hyperlipidemia}

In 2005, the crude incidence of hyperlipidemia in the MS population was 701.8, while it was 1,045.2 in the matched population (figure 1, A and B). Adjusting for year and sex, the agestandardized incidence rate of hyperlipidemia was 36\% lower in the MS population than in the matched population over the period 1995-2005 (IRR 0.64; 0.49-0.84, figure 4). This finding was consistent across age groups (data not shown). The age-standardized incidence of hyperlipidemia was $43 \%$ lower in women than men (IRR 0.66; 0.57-0.77, figure e-11). The age-standardized incidence of hyperlipidemia increased over time in both populations (IRR per year 1.04; 1.01-1.08, figure e-12).

\section{Ischemic heart disease}

In 2005, the crude incidence of IHD in the MS population was 690.5, while it was 610.2 in the matched population (figure 1, A and B). Adjusting for year and sex, the age-standardized incidence of heart disease did not differ between the populations (IRR 1.00; 0.94-1.06, figure e-13), but was $56 \%$ lower in women than men (IRR 0.54; 0.50-0.60, figure e-14). The age-standardized incidence of IHD was stable or declined very slightly over time (IRR $0.99 ; 0.98-1.00$, figure e-15).

Figure 4 Forest plot of the adjusted association of hyperlipidemia incidence and population, 1995-2005

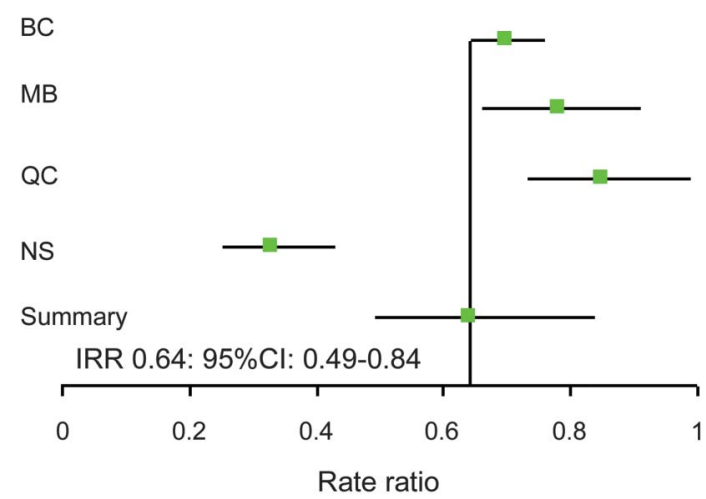

$\tau^{2}=0.070, I^{2}=91.9(p<0.0001) . \mathrm{BC}=$ British Columbia; $\mathrm{Cl}=$ confidence interval; IRR = incidence rate ratio; $\mathrm{MB}=$ Manitoba; NS = Nova Scotia; $\mathrm{QC}=$ Quebec. 


\section{Persons with MS in the lowest age group had a substantially increased risk of IHD that was attenuated at older ages.}

Age-specific incidence rates differed between the populations. Among those aged 20-44 years, the incidence of IHD was 59\% higher in the MS population (IRR 1.59; 1.19-2.11, figure e-16), but did not differ among those aged $\geq 60$ years (IRR $1.01 ; 0.97-1.06$ ).

\section{DISCUSSION}

In this population-based study, we estimated the incidence of 4 major conditions-diabetes, hypertension, hyperlipidemia, and IHD_-in MS and reference cohorts. Consistent with expectations for the Canadian population, ${ }^{2}$ the crude incidence rates of all comorbidities increased with age in the matched populations, and were higher in men than women. Findings were similar in the MS population. The incidence of vascular comorbidity varied across provinces, as previously observed in the Canadian population, ${ }^{13}$ likely reflecting differences in health behaviors and social factors. The incidence of diabetes and hyperlipidemia rose in the MS and matched populations over the 10-year study period. Although the rising rates of diabetes in the matched populations were consistent with those of the Canadian population, ${ }^{14}$ the incidence rates of diabetes and hyperlipidemia rose faster in the MS population.

In 2005, the crude incidence of diabetes in the MS population was 765.9 per 100,000 persons, slightly exceeding that of the matched population that year $(740.7 / 100,000)$. Our estimate falls within the bounds of 2 prior studies, although their estimates of the incidence of diabetes in persons with MS varied between 1 and 1,010 per 10,000 persons. ${ }^{1}$ One Danish study reported the incidence of hypertension to be 373 per 100,000 population in an incident MS cohort, ${ }^{15}$ an estimate substantially lower than we observed. However, the Danish study used data from hospitalizations rather than outpatient care for much of the study period, potentially underestimating the incidence of hypertension. In 2005, we found that the crude incidence of IHD in the MS population was 690.5 per 100,000 persons, consistent with our prior report in Manitoba for an incident, rather than prevalent, MS cohort. ${ }^{16}$ Two Nordic studies reported the incidence of myocardial infarction in incident MS cohorts to range from 236 to 275 per 100,000 population (reviewed in reference 1). These lower estimates reflect the restriction of cases to myocardial infarction, and may also reflect worldwide variation in the burden of IHD. ${ }^{17}$

Over the 10-year study period, the incidence of diabetes did not differ between the MS and matched populations, while the incidence rates of hypertension and of hyperlipidemia were lower in the MS population, but these associations changed over time. The incidence of diabetes rose 3 times faster in the MS than in the matched population over time, such that by 2005 the incidence of diabetes was higher in the MS population. This rising incidence might reflect improved ascertainment in the MS population over time as compared to the general population. However, this should have also been expected for the other comorbidities studied, and yet the findings clearly differed among them. Consistent with the aforementioned Danish study, ${ }^{15}$ we found that the incidence rate of hypertension remained lower in the MS population than the matched population throughout the study period. However, this difference was primarily due to a lower incidence of hypertension for persons with MS aged $\geq 60$ years.

Over the 10-year study period, the incidence of IHD did not differ between populations, but age-specific differences existed. Persons with MS in the lowest age group had a substantially increased risk of IHD that was attenuated at older ages. One possible explanation may be more frequent health care contacts for those with MS leading to earlier or more frequent diagnosis of IHD. However, physician visits have declined faster in the MS population over time than in the 


\section{Growing evidence suggests that vascular comorbidities are associated with more rapid disability progression in patients with MS.}

general population, ${ }^{18}$ and most of the Canadian general population has regular contact with the health system. Further, this was only observed for IHD in younger persons with MS. True differences in risk may also exist. Such was suggested by previous findings that the risk of myocardial infarction was increased during the first year after MS diagnosis (IRR = 1.84; 95\% CI 1.28-2.65) in an incident cohort. ${ }^{15}$ The associations between MS and IHD may reflect shared environmental and genetic factors, or be secondary to MS. Smoking and obesity are risk factors for $\mathrm{MS}^{3}$ and IHD, ${ }^{19}$ and physical inactivity after MS onset may also increase the risk of IHD. Persons with MS are more likely to smoke, be overweight or obese, and be less physically active than the general population. ${ }^{3}$ Other immune-mediated diseases such as rheumatoid arthritis increase the risk of IHD independent of vascular risk factors including diabetes, hypertension, hyperlipidemia, and smoking, presumably due to inflammation. ${ }^{20}$ HLA alleles are associated with the risk of MS and are also implicated in the increased risk of IHD in rheumatoid arthritis ${ }^{21}$; such associations should be evaluated in MS.

The rising incidence of comorbidity with age and over time is highly relevant to clinical care in MS. Growing evidence suggests that vascular comorbidities are associated with more rapid disability progression in patients with MS. ${ }^{3}$ Risks of adverse effects for some therapies are also increased in the presence of comorbidities such as cardiac disease or diabetes; thus the risks of therapies may change as individuals develop new comorbidities. As some disease-modifying therapies also increase the risk of comorbidities such as hypertension, it is important to determine the incidence of vascular comorbidities before these therapies are widely used, so as to better identify their effects in real-world safety and effectiveness studies, beyond clinical trials.

Limitations of this study should be considered. It was not feasible to include all Canadian provinces; however, we captured $43 \%$ of the Canadian population. Administrative data are not collected for research purposes, but we have previously validated our case definitions for the comorbidities studied. ${ }^{10}$ The need to suppress small cell sizes for privacy requirements and the naturally lower incidences in younger individuals meant our age groups were broad. Nonetheless, our study provides the age-specific incidence estimates lacking in the literature. We did not evaluate the reasons for the observed differences between populations, or the potentially complex relationships between these comorbidities and health behaviors. Finally, we lacked information regarding clinical characteristics of the MS population such as subtype and disease duration and could not evaluate associations between clinical characteristics and the incidence of vascular comorbidities.

Within the MS population, as in the general population, men and those at older ages are at increased risk of developing vascular comorbidities. This will become increasingly important as the peak prevalence of MS shifts to older ages. ${ }^{9}$ The rising incidence rates of diabetes and hyperlipidemia are concerning given their potential adverse effects on outcomes. ${ }^{3}$ Programs to systematically prevent and treat these conditions in the MS population are needed and will require specific attention to health behaviors, using collaborative models of care.

\section{REFERENCES}

1. Marrie RA, Reider N, Cohen J, et al. A systematic review of the incidence and prevalence of cardiac, cerebrovascular and peripheral vascular disease in multiple sclerosis. Mult Scler J 2015;21:318-331.

2. Broemeling A, Watson DE, Prebtani F; on behalf of the Councillors of the Health Outcomes Steering Committee of the Health Council of Canada. Population patterns of chronic health conditions, comorbidity and health care use in Canada: implications for policy and practice. Healthc Q 2008;11:70-76.

3. Tettey P, Simpson S Jr, Taylor BV, van der Mei IAF. Vascular comorbidities in the onset and progression of multiple sclerosis. J Neurol Sci 2014;347:23-33. 
4. Statistics Canada. Population by Year, by Province and Territory (Number). Available at: http://www. statcan.gc.ca/tables-tableaux/sum-som/101/cst01/demo02a-eng.htm. Accessed January 4, 2016.

5. British Columbia Ministry of Health. Discharge Abstract Database (Hospital Separations) [online]; 2012. Available at: http://www.popdata.bc.ca/data. Accessed April 1, 2015.

6. British Columbia Ministry of Health. Medical Services Plan (Msp) [online]; 2012. Available at: http:// www.popdata.bc.ca/data. Accessed April 1, 2015.

7. British Columbia Ministry of Health. Consolidation File (Msp Registration \& Premium Billing) [online]; 2012. Available at: http://www.popdata.bc.ca/data. Accessed April 1, 2015.

8. Dormuth CR, Hemmelgarn BR, Paterson JM, et al. Use of high potency statins and rates of admission for acute kidney injury: multicenter, retrospective observational analysis of administrative databases. BMJ 2013;346:f880.

9. Marrie RA, Fisk J, Stadnyk K, et al. The incidence and prevalence of multiple sclerosis in Nova Scotia, Canada. Can J Neurol Sci 2013;40:824-831.

10. Marrie RA, Fisk JD, Stadnyk KJ, et al. Performance of administrative case definitions for comorbidity in multiple sclerosis in Manitoba and Nova Scotia. Chronic Dis Inj Can 2014;34:145-153.

11. Yasui Y, Liu Y, Neglia J, et al. A methodological issue in the analysis of second-primary cancer incidence in long-term survivors of childhood cancers. Am J Epidemiol 2003;158:1108-1113.

12. Neyeloff J, Fuchs S, Moreira L. Meta-analyses and forest plots using a Microsoft Excel spreadsheet: step-by-step guide focusing on descriptive data analysis. BMC Res Notes 2012;5:52.

13. Filate WA, Johansen HL, Kennedy CC, Tu JV. Regional variations in cardiovascular mortality in Canada. Can J Cardiol 2003;19:1241-1248.

14. Public Health Agency of Canada. Diabetes in Canada: Factors and Figures from a Public Health Perspective. Ottawa: Public Health Agency of Canada; 2011:2011.

15. Christiansen CF, Christensen S, Farkas DK, Miret M, Sørensen HT, Pedersen L. Risk of arterial cardiovascular diseases in patients with multiple sclerosis: a population-based cohort study. Neuroepidemiology 2010;35:267-274.

16. Marrie RA, Yu BN, Leung S, et al. Prevalence and incidence of ischemic heart disease in multiple sclerosis: a population-based validation study. Mult Scler Relat Disord 2013;2:355-361.

17. Moran AE, Forouzanfar MH, Roth GA, et al. The global burden of ischemic heart disease in 1990 and 2010: the global burden of disease 2010 study. Circulation 2014;129:1493-1501.

18. Marrie RA, Yu N, Wei Y, Elliott L, Blanchard J. High rates of physician services utilization at least five years before multiple sclerosis diagnosis. Mult Scler J 2013;19:1113-1119.

19. Greenland P, Knoll MD, Stamler J, et al. Major risk factors as antecedents of fatal and nonfatal coronary heart disease events. JAMA 2003;290:891-897.

20. Crowson CS, Nicola PJ, Kremers HM, et al. How much of the increased incidence of heart failure in rheumatoid arthritis is attributable to traditional cardiovascular risk factors and ischemic heart disease? Arthritis Rheum 2005;52:3039-3044.

21. Mattey DL, Thomson W, Ollier WER, et al. Association of DRB1 shared epitope genotypes with early mortality in rheumatoid arthritis: results of eighteen years of followup from the early rheumatoid arthritis study. Arthritis Rheum 2007;56:1408-1416.

Received July 30, 2015. Accepted in final form October 26, 2015.

\section{ACKNOWLEDGMENT}

The results and conclusions presented are those of the authors. No official endorsement by Manitoba Health, Population Data BC, or the Regie d'Assurance Maladie du Quebec is intended or should be inferred. Some data used in this report were made available by Health Data Nova Scotia of Dalhousie University. Although this research uses data obtained from the Nova Scotia Department of Health and Wellness, the observations and opinions expressed of those of the authors and do not represent those of either Health Data Nova Scotia or the Department of Health and Wellness. The authors thank the following contributors: Patricia Caetano, PhD (University of Manitoba, policy consultant); Nicholas Hall, BSc (University of Manitoba, study coordinator); Feng Zhu, PhD (University of British Columbia, analytic support); Elaine Kingwell, PhD (University of British Columbia, study coordination support), Karen Stadnyk, MSc (Dalhousie University, study coordinator), Yan Wang (Dalhousie University, analytic support), Bin Zhu (McGill University, analyst); Aruni Tennakoon (University of Manitoba, analyst); Stella Leung (University of Manitoba, analyst).

\section{AUTHOR CONTRIBUTIONS}

The corresponding author (RAM) takes responsibility for the integrity of the data and the accuracy of the data analysis. The analysts and principal investigators at each site had full access to the data at each site 
(British Columbia: Helen Tremlett, Aruni Tennakoon, Stella Leung; Manitoba: Ruth Ann Marrie, Aruni Tennakoon; Quebec: Christina Wolfson, Bin Zhu; Nova Scotia: John Fisk, Yan Wang). Ruth Ann Marrie, John Fisk, Christina Wolfson, Helen Tremlett, and Sharon Warren designed the study and obtained funding. All authors contributed to the interpretation of the data. Ruth Ann Marrie drafted the manuscript. All authors revised the manuscript and approved of the final version to be published.

\section{STUDY FUNDING}

Supported in part by the Canadian Institutes of Health Research (CIBG 101829), the Rx \& D Health Research Foundation, a Don Paty Career Development award from the Multiple Sclerosis Society of Canada (to RAM), and Manitoba Research Chair from Research Manitoba (to RAM). The funding sources had no role in the study design, collection, analysis, or interpretation of the data, or in the decision to submit the article for publication.

\section{DISCLOSURES}

R.A. Marrie serves on the editorial boards of Neurology ${ }^{\circledR}$ and Multiple Sclerosis Journal and has received research support from Sanofi-Aventis, Canadian Institutes of Health Research (CIHR), Public Health Agency of Canada, Research Manitoba, Multiple Sclerosis Society of Canada, National Multiple Sclerosis Society, Multiple Sclerosis Scientific Foundation, Rx \& D Health Research Foundation, and Consortium of Multiple Sclerosis Centers. J. Fisk has received travel expenses and honorarium from EMD Serono for workshop participation; has received research support from CIHR, MS Society of Canada, and National MS Society; and receives license fee payments for a Fatigue Impact Scale and Daily Fatigue Impact Scale (MAPI Research Trust). H. Tremlett is funded by the Multiple Sclerosis Society of Canada (Don Paty Career Development Award) and is a Michael Smith Foundation for Health Research Scholar and the Canada Research Chair for Neuroepidemiology and Multiple Sclerosis. She has received research support from the National Multiple Sclerosis Society, the Canadian Institutes of Health Research, and the UK MS Trust, and speaker honoraria and/or travel expenses to attend conferences from the Consortium of MS Centres, the National MS Society, Bayer Pharmaceuticals, Teva Pharmaceuticals, ECTRIMS, UK MS Trust, the Chesapeake Health Education Program, US Veterans Affairs, Novartis Canada, Biogen Idec, and the American Academy of Neurology. Unless otherwise stated, all speaker honoraria are either donated to an MS charity or to an unrestricted grant for use by her research group. C. Wolfson has received a speaker honorarium from Novartis; serves on the editorial board of the Journal of Military, Veteran and Family Health; and receives research support from CIHR, Canada Foundation for Innovation, National Multiple Sclerosis Society, and Multiple Sclerosis Society of Canada. S. Warren receives research support from CIHR and has provided an expert opinion paper on trauma and MS on behalf of a legal firm. J. Blanchard receives research support from the Multiple Sclerosis Society of Canada, CIHR, BMGF, Bill \& Melinda Gates Foundation, Canadian International Development Agency, and the United States Agency for International Development. S.B. Patten has received honoraria for reviewing investigator-initiated grant applications submitted to Lundbeck and Pfizer; has received speaker honoraria from Teva and Lundbeck; serves as Editor-in-Chief for the Canadian Journal of Psychiatry, as Senior Associate Editor for Epidemiology and Psychiatric Sciences, and on the editorial advisory boards of Chronic Diseases in Canada and Clinical Practice and Epidemiology in Mental Health; receives publishing royalties for Epidemiology for Canadian Students (Brush Education, 2015); is the recipient of a salary support award (Senior Health Scholar) from Alberta Innovates, Health Solutions; and receives research support from CIHR, Hotchkiss Brain Institute, Pfizer Canada, Alberta Innovates/Health Solutions, Alberta Health Services, and the Alberta Collaborative Research Grants Initiative. Full disclosure form information provided by the authors is available with the full text of this article at Neurology.org/cp.

\section{Related articles from AAN physician and patient resources}

\section{Neurology ${ }^{\circledR} \quad$ Neurology.org}

Comorbidity increases the risk of hospitalizations in MS: Prevention opportunities January 27, 2015;84:335-336. 


\section{Neurology ${ }^{\circ}$ Clinical Practice}

Differing trends in the incidence of vascular comorbidity in MS and the general population

Ruth Ann Marrie, John Fisk, Helen Tremlett, et al.

Neurol Clin Pract 2016;6;120-128 Published Online before print March 8, 2016

DOI 10.1212/CPJ.0000000000000230

This information is current as of March 8, 2016

Neurol Clin Pract is an official journal of the American Academy of Neurology. Published continuously since 2011, it is now a bimonthly with 6 issues per year. Copyright ( 2016 American Academy of Neurology. All rights reserved. Print ISSN: 2163-0402. Online ISSN: 2163-0933.

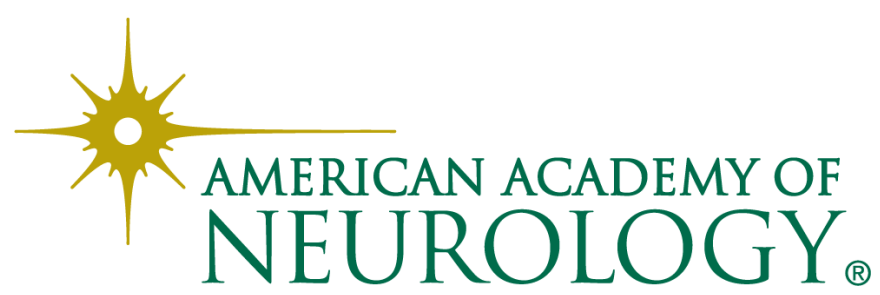




\section{Updated Information \& Services}

\section{Supplementary Material}

\section{References}

Citations

Subspecialty Collections

\section{Permissions \& Licensing}

\section{Reprints}

including high resolution figures, can be found at: http://cp.neurology.org/content/6/2/120.full.html

Supplementary material can be found at: http://cp.neurology.org/content/suppl/2016/03/08/CPJ.0000000000000 230.DC2 http://cp.neurology.org/content/supp1/2016/03/08/CPJ.0000000000000 230.DC1

This article cites 16 articles, 2 of which you can access for free at: http://cp.neurology.org/content/6/2/120.full.html\#\#ref-list-1

This article has been cited by 3 HighWire-hosted articles: http://cp.neurology.org/content/6/2/120.full.html\#\#otherarticles

This article, along with others on similar topics, appears in the following collection(s):

\section{Cardiac; see Cerebrovascular Disease/Cardiac}

http://cp.neurology.org//cgi/collection/cardiac_see_cerebrovascular_dis ease-cardiac

\section{Cohort studies}

http://cp.neurology.org//cgi/collection/cohort_studies

\section{Incidence studies}

http://cp.neurology.org//cgi/collection/incidence_studies

Multiple sclerosis

http://cp.neurology.org//cgi/collection/multiple_sclerosis

Information about reproducing this article in parts (figures,tables) or in its entirety can be found online at:

http://cp.neurology.org/misc/about.xhtml\#permissions

Information about ordering reprints can be found online: http://cp.neurology.org/misc/addir.xhtml\#reprintsus

Neurol Clin Pract is an official journal of the American Academy of Neurology. Published continuously since 2011, it is now a bimonthly with 6 issues per year. Copyright (C) 2016 American Academy of Neurology. All rights reserved. Print ISSN: 2163-0402. Online ISSN: 2163-0933.



